\title{
Synthesis of silver nanoparticles in montmorillonite and their antibacterial behavior
}

\author{
This article was published in the following Dove Press journal: \\ International Journal of Nanomedicine \\ 23 March 20II \\ Number of times this article has been viewed
}

\author{
Kamyar Shameli' \\ Mansor Bin Ahmad' \\ Mohsen Zargar ${ }^{2}$ \\ Wan Md Zin Wan Yunus' \\ Abdolhossein Rustaiyan ${ }^{3}$ \\ Nor Azowa Ibrahim' \\ 'Department of Chemistry, \\ Faculty of Science, Universiti Putra \\ Malaysia, Serdang, Selangor, Malaysia; \\ ${ }^{2}$ Department of Biology, Faculty of \\ Science, Islamic Azad University, Qom \\ Branch, Qom, Iran; ${ }^{3}$ Department of \\ Chemistry, Science and Research \\ Branch, Islamic Azad University, \\ Tehran, Iran
}

\begin{abstract}
Silver nanoparticles (Ag NPs) were synthesized by the chemical reducing method in the external and interlamellar space of montmorillonite (MMT) as a solid support at room temperature. $\mathrm{AgNO}_{3}$ and $\mathrm{NaBH}_{4}$ were used as a silver precursor and reducing agent, respectively. The most favorable experimental conditions for synthesizing Ag NPs in the MMT are described in terms of the initial concentration of $\mathrm{AgNO}_{3}$. The interlamellar space limits changed little $(\mathrm{d}$-spacing $=1.24-1.47 \mathrm{~nm})$; therefore, Ag NPs formed on the MMT suspension with d-average $=4.19-8.53 \mathrm{~nm}$ diameter. The Ag/MMT nanocomposites (NCs), formed from $\mathrm{AgNO}_{3} / \mathrm{MMT}$ suspension, were characterizations with different instruments, for example UVvisible, PXRD, TEM, SEM, EDXRF, FT-IR, and ICP-OES analyzer. The antibacterial activity of different sizes of Ag NPs in MMT were investigated against Gram-positive, ie, Staphylococcus aureus and methicillin-resistant S. aureus (MRSA) and Gram-negative bacteria, ie, Escherichia coli, Escherichia coli $\mathrm{O} 157: \mathrm{H} 7$, and Klebsiella pneumoniae, by the disk diffusion method using Mueller-Hinton agar (MHA). The smaller Ag NPs were found to have significantly higher antibacterial activity. These results showed that Ag NPs can be used as effective growth inhibitors in different biological systems, making them applicable to medical applications.
\end{abstract}

Keywords: silver nanoparticles, nanoparticles, montmorillonite, antibacterial activity, MuellerHinton agar

\section{Introduction}

Nanoparticles are important materials for fundamental studies and diversified technical applications, because of their size-dependent properties or highly active performance due to the large surface areas; but when pure nanoparticles are used alone, they present some common problems, eg, agglomeration between nanoparticles. ${ }^{1}$ To overcome agglomeration, preparation of nanoparticles based on clay compounds, in which nanoparticles are supported within the interlamellar spaces of clay and/or on its external surfaces, is one of the most effective solutions. ${ }^{2-4}$ Synthesis of metal nanoparticles on solid supports such as smectite clays is a suitable way to prepare practically applicable supported particles as well as to control the particle size. Smectite clays have excellent swelling and adsorption ability, which is especially interesting for the impregnation of antibacterial-active nano-size metals in the interlamellar space of clay. ${ }^{5,6}$ Montmorillonite (MMT) as lamellar clay has intercalation, swelling, and ion exchange properties. Its interlayer space has been used for the synthesis of material and biomaterial nanoparticles. ${ }^{7-9}$
Correspondence: Kamyar Shameli Department of Chemistry, Faculty of Science, Universiti Putra Malaysia, 43400, Serdang, Selangor, Malaysia Tel 60389466044

Fax 60389466043

Email kamyarshameli@gmail.com 
The silver nanoparticles (Ag NPs) deposited on inorganic substrates, such as $\mathrm{TiO}_{2}, \mathrm{SiO}_{2}, \mathrm{Al}_{2} \mathrm{O}_{3}, \mathrm{SiO}_{2} / \mathrm{TiO}_{2}, \mathrm{SiO}_{2} / \mathrm{B}_{2} \mathrm{O}_{3}$, and $\mathrm{BaTiO}_{3},{ }^{10}$ and phyllosilicates such as MMT, ${ }^{11-13}$ kaolinite, ${ }^{14}$ and synthetic layered silicate such as laponite, ${ }^{15}$ have also been used as carriers for Ag/nanocomposites. For the synthesis of Ag NPs in the solid substrate, $\mathrm{AgNO}_{3}$ is often used as the primary source of $\mathrm{Ag}^{+}$. Among the numerous ways of $\mathrm{Ag}^{+}$reduction are: $\gamma$-ray, ${ }^{16} \mathrm{UV},{ }^{17}$ or laser irradiations, ${ }^{18}$ heating, ${ }^{19}$ electrochemical reduction, ${ }^{20}$ application of reducing chemicals, such as hydrazine, ${ }^{21}$ sodium borohydride, ${ }^{14}$ glycerol, ${ }^{12,22} \mathrm{~N}, \mathrm{~N}$-dimethylformamide, ${ }^{23}$ glucose,${ }^{24}$ ethylene glycol, ${ }^{25}$ formaldehyde,${ }^{26}$ and sodium in liquid ammonia. ${ }^{27}$

The investigation of the antibacterial activity of Ag NPs has regained importance due to increasing bacterial resistance to antibiotics. ${ }^{28}$ The interactions of Ag NPs with bacteria depend on the size and shape of the nanoparticles, but the bactericidal mechanism of Ag NPs is not clear. ${ }^{29}$ The antibacterial activity of the Ag NPs can be used in several medical applications, for example, to reduce infections in burn treatment, ${ }^{30}$ and human skin. ${ }^{31,32}$

Based on our previous work, therefore, Ag NPs in the interlayer space of MMT were synthesized according to two different methods, the chemical and physical reduction techniques, using $\beta$-D-Glucose, ${ }^{33} \mathrm{NaBH}_{4},{ }^{34,35} \mathrm{UV},{ }^{36-38}$ and $\gamma$-irradiation ${ }^{39}$ methods as the reducing agents. In this study, the different-sized Ag NPs were synthesized in the lamellar space of the MMT in the aqueous solution, by changing the initial concentration of $\mathrm{Ag}^{+}$ions at room temperature. We used the MMT as the protective colloid preventing the Ag NPs from aggregation, and found that MMT also assisted in the chemical reducing process of silver. In addition, the antibacterial activities of $\mathrm{AgNO}_{3} / \mathrm{MMT}$ and $\mathrm{Ag}$ NPs formed in the lamellar space of MMT were investigated and compared with one another. By this method we were able to obtain Ag NPs with different sizes and dissimilar antibacterial activities.

\section{Experimental}

\section{Chemicals}

All reagents in this work were of analytical grades and used as received without further purification. $\mathrm{AgNO}_{3}$ (99.98\%) was used as the silver precursor, which was obtained from Merck (Germany). MMT powder, used as a solid support for Ag NPs, was purchased from Kunipa-F (Japan), whereas the $\mathrm{NaBH}_{4}(98.5 \%)$ and $\mathrm{HNO}_{3}(>90 \%)$ were used as reducing and digestion agents obtained from Sigma-Aldrich (St Louis, MO). All the aqueous solutions were prepared in double distilled water.

\section{Synthesis of Ag/MMT nanocomposites (NCs) by using $\mathrm{NaBH}_{4}$}

For the synthesis of Ag/MMT NCs, the silver contents of the samples were 0.5 (S1), 1.0 (S2), 1.5 (S3), 2.0 (S4), and $5.0 \mathrm{~g}$ (S5) Ag/100 g MMT. Constant amounts of MMT were suspended in different volumes of $1 \times 10^{-3} \mathrm{M} \mathrm{AgNO}_{3}$ solution and stirred for 24 hours at room temperature to obtain the $\mathrm{AgNO}_{3} / \mathrm{MMT}$ suspension and completed cation exchange. A freshly prepared $\mathrm{NaBH}_{4}\left(4 \times 10^{-2} \mathrm{M}\right)$ solution was then added to the suspensions under continuous stirring to reach a constant $\mathrm{AgNO}_{3} / \mathrm{NaBH}_{4}$ molar ratio (1:4). After the addition of the reducing agent, stirring continued for a further hour. The suspensions of Ag/MMT NCs obtained were then centrifuged at $15,000 \mathrm{rpm}$ for 20 minutes, and the precipitates washed 4 times using double distilled water in order to remove the silver ion residue, and dried overnight at $40^{\circ} \mathrm{C}$ under vacuum overnight.

\section{Characterization methods}

\section{and instruments}

The UV-visible spectra were recorded over the range of $300-700 \mathrm{~nm}$ by utilizing the Lambda 25 -Perkin Elmer, UV-visible spectrophotometer. The structures of the produced Ag/MMT NCs were examined using Shimadzu PXRD-6000, powder X-ray diffraction. The changes in the interlamellar spacing of MMT and Ag/MMT NCs were also studied by utilizing PXRD in the angle range of $2^{\circ}<2 \theta<12^{\circ}$. In addition, the interlamellar spaces were calculated from the PXRD peak positions using Bragg's law. A wavelength $(\lambda)$ of $0.15418 \mathrm{~nm}$ was used for these measurements. The PXRD patterns were recorded at a scan speed of $2 \mathrm{~min}^{-1}$. Moreover, TEM observations were carried out on a Hitachi H-7100 electron microscope and the particle size distributions were determined using the UTHSCSA Image Tool version 3.00 program. SEM was performed using the Philips XL-30 instrument to study the morphology of MMT and $\mathrm{Ag}$ /MMT NCs (S2, S4, and S5). EDXRF was carried out on a Shimadzu EDX-700HS spectrometer. In order to determine the approximate efficiency for each Ag/MMT NCs (S1-S5), the ICP-OES analyzer was used in this study. A modified digestion method was used to quantify the amount of Ag NPs conversion to $\mathrm{Ag}^{+}$in the MMT. An air-dry mass of each $\mathrm{Ag} / \mathrm{MMT}$ NCs was submerged in a solution of $10 \mathrm{~mL}$ of pure reagent grade nitric acid and $10 \mathrm{~mL}$ of double distilled water. After the observed glass containers were placed over the digestion beakers, the solutions were heated to approximately $80^{\circ} \mathrm{C}$ for 15 minutes and allowed to react. The digestion solutions were allowed to cool to room temperature and then 
filtered through a glass fibre filter (Qualitative \#2, Whatman) and diluted in $100 \mathrm{~mL}$ in volumetric flasks. ${ }^{40}$ The elemental analysis of as-synthesized Ag NPs was quantified by using an inductively coupled plasma-optical emission spectrophotometer (ICP-OES) model Perkin Elmer-Optima 2000DV. Meanwhile, the FT-IR spectra were recorded over the range of $400-4000 \mathrm{~cm}^{-1}$ utilizing the Series 100 Perkin Elmer FT-IR 1650 spectrophotometer. After the reactions, the samples were centrifuged with a high-speed centrifuge machine (Avanti J25, Beckman).

\section{Evaluation of antibacterial activity}

The in vitro antibacterial activity of the samples was evaluated according to the disc diffusion method using Mueller-Hinton agar (MHA) with determination of inhibition zones in millimetres, which conformed to the recommended standards of the National Committee for Clinical Laboratory Standards (NCCLS; now renamed the Clinical and Laboratory Standards Institute, CLSI, 2000). Escherichia coli (ATCC 25922), E. coli O157:H7 (ATCC 43895), Klebsiella pneumoniae (ATCC 13883), Staphylococcus aureus (ATCC 25923), and methicillin-resistant S. aureus (MRSA) (ATCC 700689) were used for the antibacterial effect assay. Briefly, the sterile paper discs (6 $\mathrm{mm})$ impregnated with $20 \mu \mathrm{L}$ of Ag/MMT NCs (S2, S4, and S5) with different treatment times were suspended in the sterile distilled water and left to dry for 24 hours at $37^{\circ} \mathrm{C}$ in a sterile condition. The bacterial suspension was prepared by making a saline suspension of isolated colonies selected from the 18 to 24 hours of tryptic soy agar plate. The suspension was adjusted to match the tube of 0.5 McFarland turbidity standard using the spectrophotometer of $600 \mathrm{~nm}$, which is equal to $1.5 \times 10^{8}$ colony-forming units $/ \mathrm{mL}$. The surface of MHA was completely inoculated using a sterile swab, steeped in the prepared suspension of bacterium. Finally, the impregnated discs were placed on the inoculated agar and incubated at $37^{\circ} \mathrm{C}$ for 24 hours. After incubation, the diameter of the growth inhibition zones was measured. Chloramphenicol (30 $\mu \mathrm{g})$ and cefotaxime $(30 \mu \mathrm{g})$ were used as the positive standards in order to control the sensitivity of the bacteria. All tests were done in triplicate.

\section{Results and discussion}

To prepare the stable Ag NPs via the chemical reducing method, the choice of a suitable stabilizer and reducing agent was important. In this research, MMT suspension was used as the appropriate support for reducing $\mathrm{AgNO}_{3} / \mathrm{MMT}$ suspension using $\mathrm{NaBH}_{4}$ as the strong reducing agent according to Equation (1) as follows. ${ }^{41}$

$\mathrm{Ag}^{+} / \mathrm{MMT}+\mathrm{BH}_{4}^{-}+3 \mathrm{H}_{2} \mathrm{O} \rightarrow \mathrm{Ag}^{\circ} / \mathrm{MMT}+\mathrm{B}(\mathrm{OH})_{3}+3.5 \mathrm{H}_{2}$

The surfaces of MMT suspension assist the Ag NPs nucleation during the reduction process. The schematic illustration of the synthesis of $\mathrm{Ag} / \mathrm{MMT} \mathrm{NCs}$ from $\mathrm{AgNO}_{3} / \mathrm{MMT}$ suspension produced by using sodium borohydride is shown in Figure 1. Meanwhile, as shown in Figure 2, the $\mathrm{AgNO}_{3} /$ MMT (S0) was colorless, but after the addition of the reducing agent to the suspensions, they turned light brown (S2), brown (S4), and dark brown (S5), indicating the formation of Ag NPs in the MMT suspensions. The formation of Ag NPs was also followed by measuring the surface plasmon resonance (SPR) bands of the $\mathrm{AgNO}_{3} / \mathrm{MMT}$ and $\mathrm{Ag} / \mathrm{MMT}$ NCs suspensions at a wavelength of 300-700 nm (Figure 2). Comparing the PXRD patterns of MMT and Ag/MMT NCs (S1, S2 and S5), in the small-angle range of $2 \theta\left(2^{\circ}<\right.$ $2 \theta<12^{\circ}$ ), indicated that the intercalated Ag NPs formed between adjacent MMT lamellar layers were smaller, but that
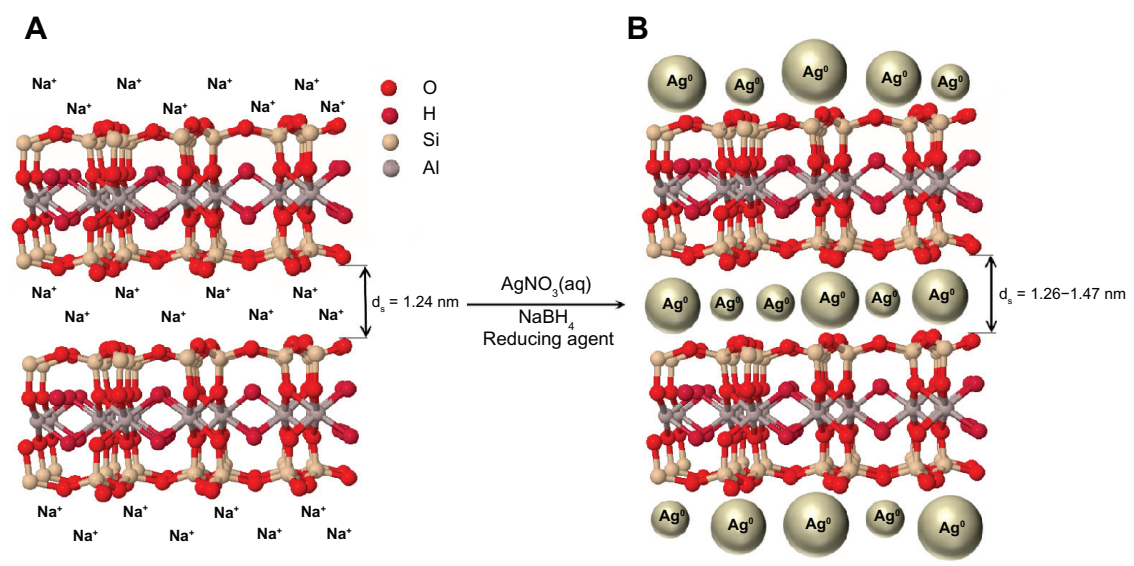

Figure I Schematic illustration of the synthesized Ag NPs in the interlayer space of MMT suspension by chemical reduction method. 


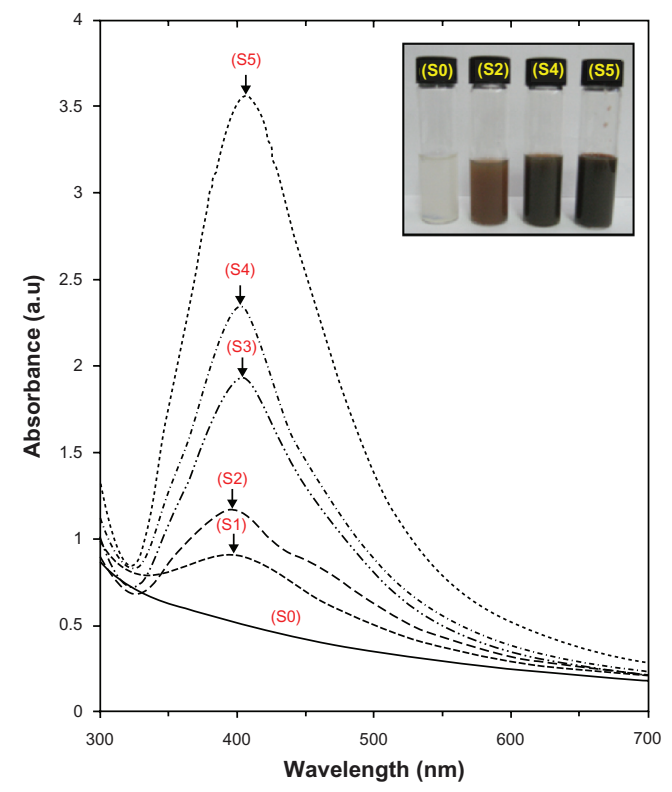

Figure 2 Photograph and UV-visible absorption spectra of Ag/MMT suspension for different $\mathrm{AgNO}_{3}$ concentrations; $0.5 \%, 1.0 \%, 1.5 \%, 2.0 \%, 5.0 \%$ (SI-S5), and (S0) $\mathrm{AgNO}_{3} / \mathrm{MMT}$ suspension.

most of the Ag NPs were formed at the MMT suspension interface (Figure 3). In addition, the PXRD patterns in the wide-angle range of $2 \theta\left(30^{\circ}<2 \theta<80^{\circ}\right)$ were also employed to determine the crystalline structures of the synthesized Ag NPs (Figure 4). The TEM images and their size distributions of Ag NPs showed that the mean diameter of the nanoparticles ranged from about 4.19 to $8.53 \mathrm{~nm}$ (Figure 5). As shown in

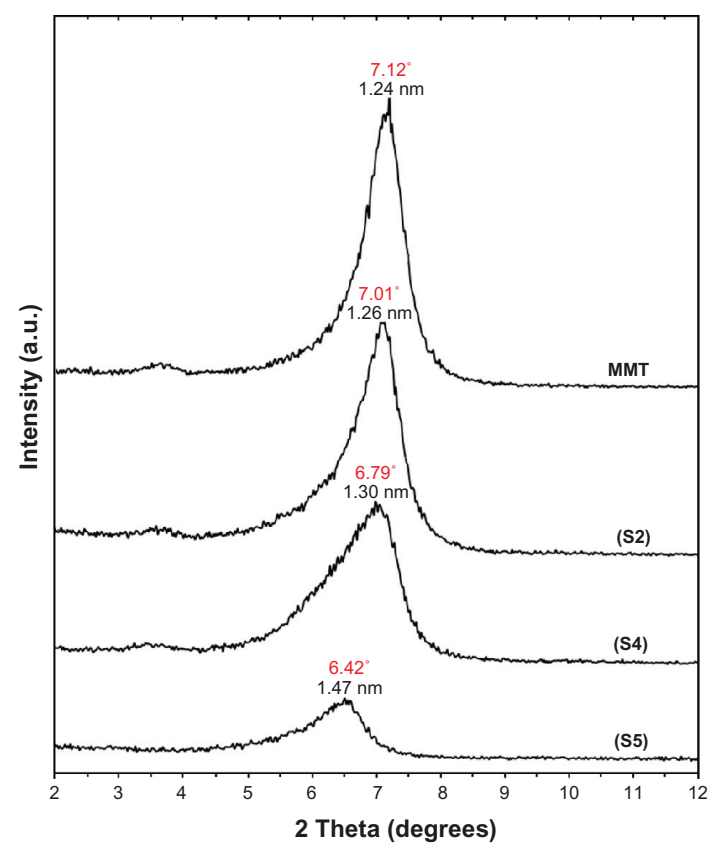

Figure 3 PXRD patterns of MMT and Ag/MMT NCs for determination of $d$-spacing at different $\mathrm{AgNO}_{3}$ concentrations: (S2) $1.0 \%$, (S4) $2.0 \%$, and (S5) $5.0 \%$.

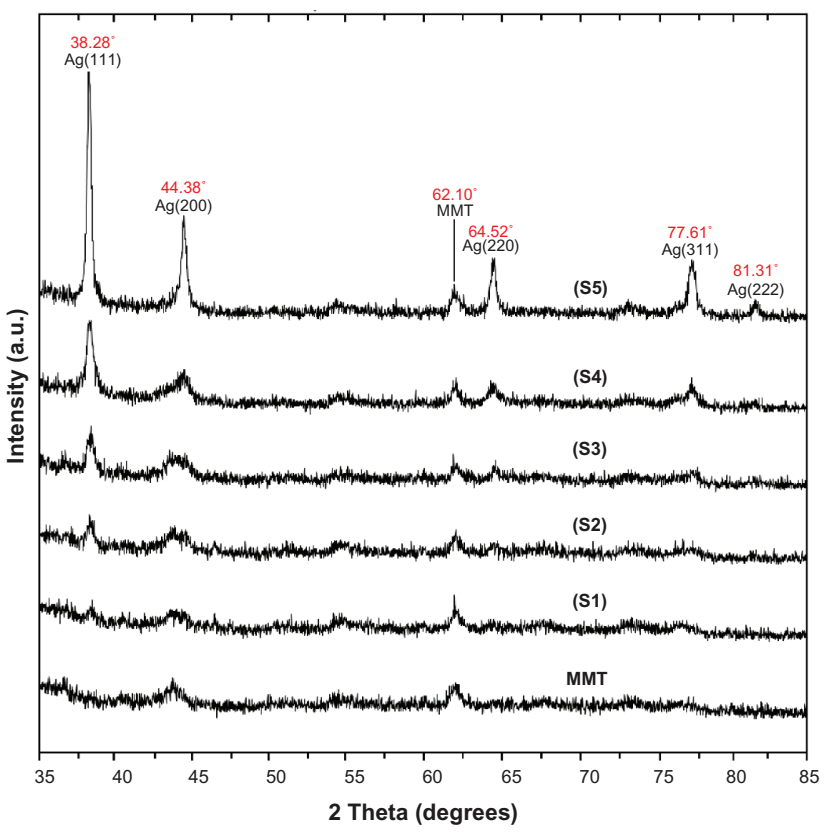

Figure 4 PXRD patterns of MMT and Ag/MMT NCs for determination of silver crystals at different $\mathrm{AgNO}_{3}$ concentrations: $0.5 \%, 1.0 \%, 1.5 \%, 2.0 \%$ and $5.0 \%$ (SI-S5).

Figure 6, the SEM images indicated that there were no structure changes between the initial MMT and Ag/MMT NCs (S2, S4, and S5). Additionally, the EDXRF spectra for the MMT and Ag/MMT NCs confirmed the presence of elemental compounds in MMT and Ag NPs with no other impurity peaks (Figures 6B and F). The chemical structures of MMT and Ag/MMT NCs were analyzed by using FT-IR spectroscopy (Figure 7). The approximate efficiency gradually increased from S1 to S5, respectively (Table 1). The antibacterial studies showed comparatively similar effects for all samples as indicated by the inhibition zone test between MMT, $\mathrm{AgNO}_{3} / \mathrm{MMT}$, and $\mathrm{Ag} / \mathrm{MMT} \mathrm{NCs}$ against different bacteria (Figure 8, Table 2).

\section{UV-visible spectroscopy}

The color of $\mathrm{AgNO}_{3} / \mathrm{MMT}$ suspensions through the reducing process using $\mathrm{NaBH}_{4}$ changed from colourless, (S0) to light brown, brown, and finally dark brown (S2, S4 and S5) respectively, which indicated the formation of Ag NPs in the MMT suspension. The silver SPR bands were detected around $400 \mathrm{~nm}$ (Figure 2). These absorption bands were assumed to correspond to the Ag NPs smaller than $10 \mathrm{~nm} .{ }^{42}$ While there was no UV-visible absorption of Ag NPs before the addition of $\mathrm{NaBH}_{4}$ in $\mathrm{S} 0$ (Figure 2), the growth of the plasmon peak at $396 \mathrm{~nm}$ indicated the formation of Ag NPs in S1. Furthermore, the gradual increase in the $\mathrm{AgNO}_{3}$ concentration from S1 to S4 also increased the corresponding peak intensities in the range of wavelength from 398 to 400 and 


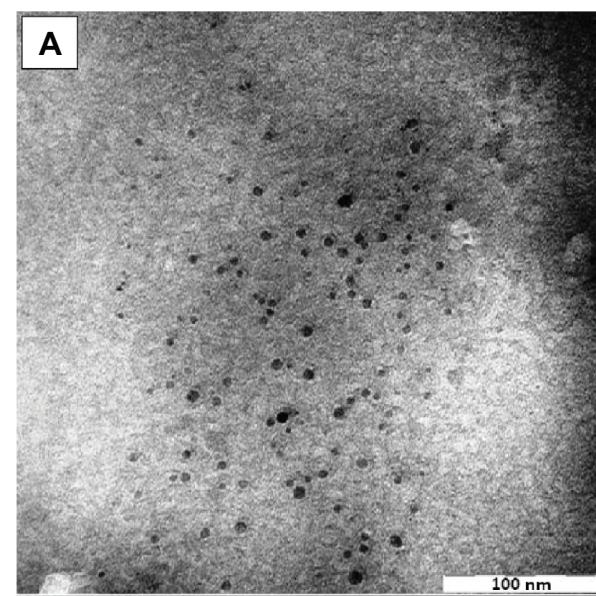

\section{B}
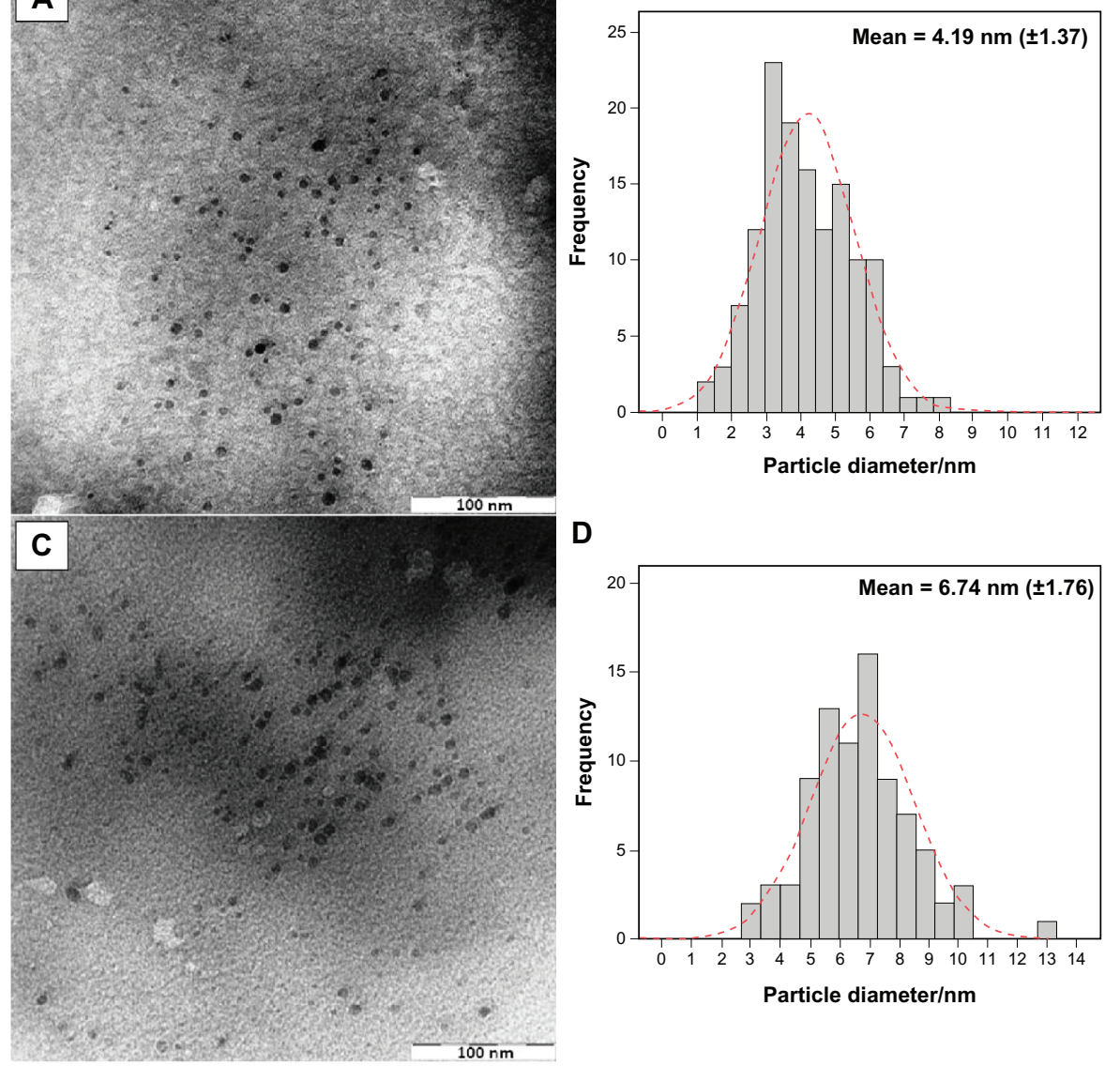

D
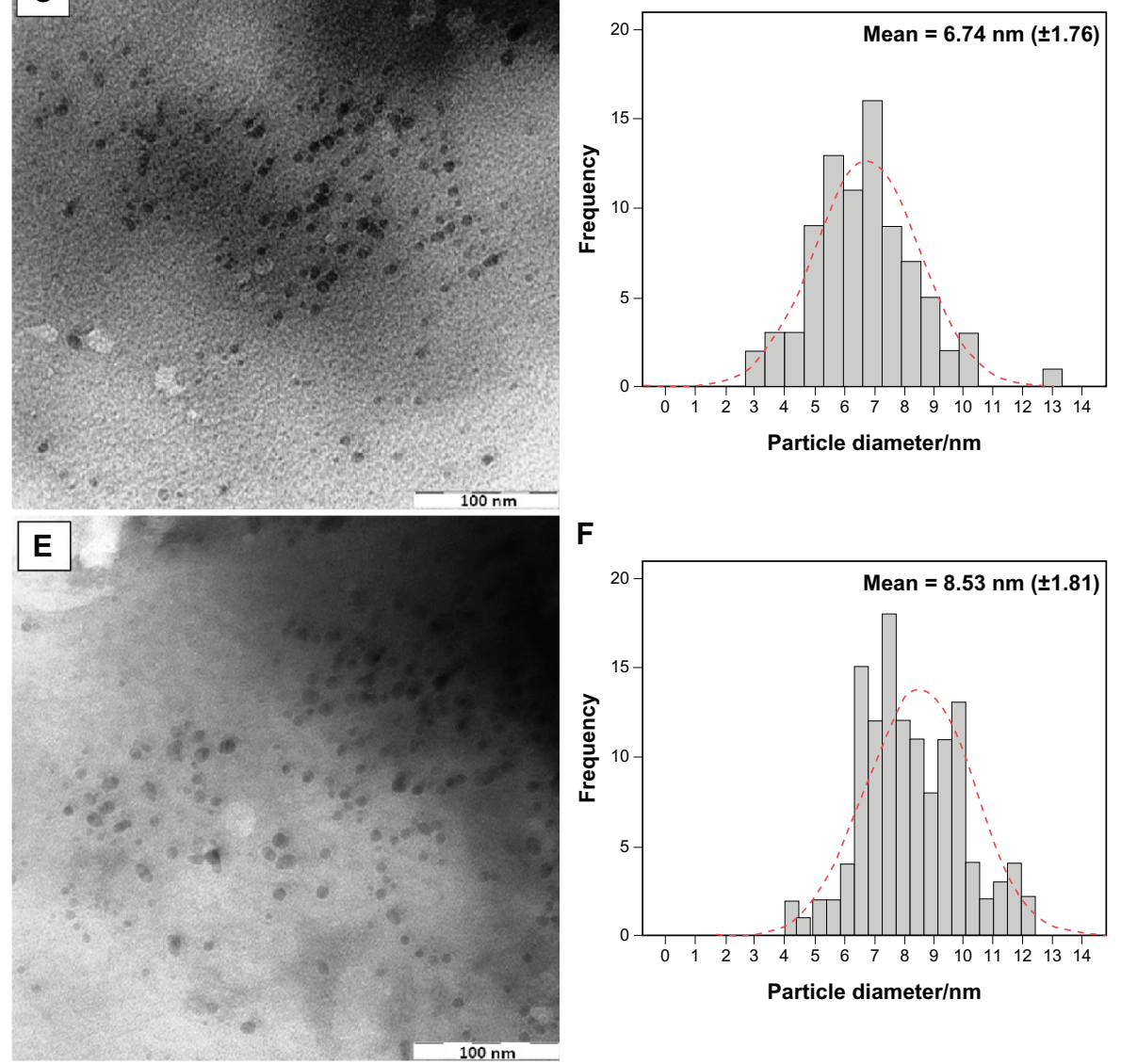

Figure 5 TEM images and corresponding particle size distribution of $\mathrm{Ag} / \mathrm{MMT} \mathrm{NCs}$ at different $\mathrm{AgNO}_{3}$ concentrations: I.0\% (A, B), 2.0\% (C, D), and 5.0\% (E, F).

$402 \mathrm{~nm}$ respectively. In S5, the absorption peak due to SPR of Ag was slightly red-shifted to higher wavelength (406 nm), which indicated the increase in the size of Ag NPs. ${ }^{43}$

\section{Powder X-ray diffraction}

As shown in Figure 3, the original d-spacing of MMT, $1.24 \mathrm{~nm}$, and in Ag/MMT NCs (S2, S4 and S5), was increased to $1.27,1.30$, and $1.47 \mathrm{~nm}$ respectively at $2 \theta$ angles of $7.12^{\circ}$ to $7.01^{\circ}, 6.79^{\circ}$, and $6.42^{\circ}$ respectively. These $d$-spacing values were direct proof that very small numbers of Ag NPs might be intercalated between adjacent MMT lamellar layers. Therefore, the Ag NPs formed at the latter location were the cause of the increase in basal spacing. In these samples, the intensities of the reflections were significantly lower, whereas their half-widths were larger than those of undoped clay minerals, whereby the highly ordered parallel lamellar structure of the mineral were disrupted by the metal nanoparticles formation. ${ }^{14}$ In addition, all the Ag/MMT NCs (S1-S5) had 

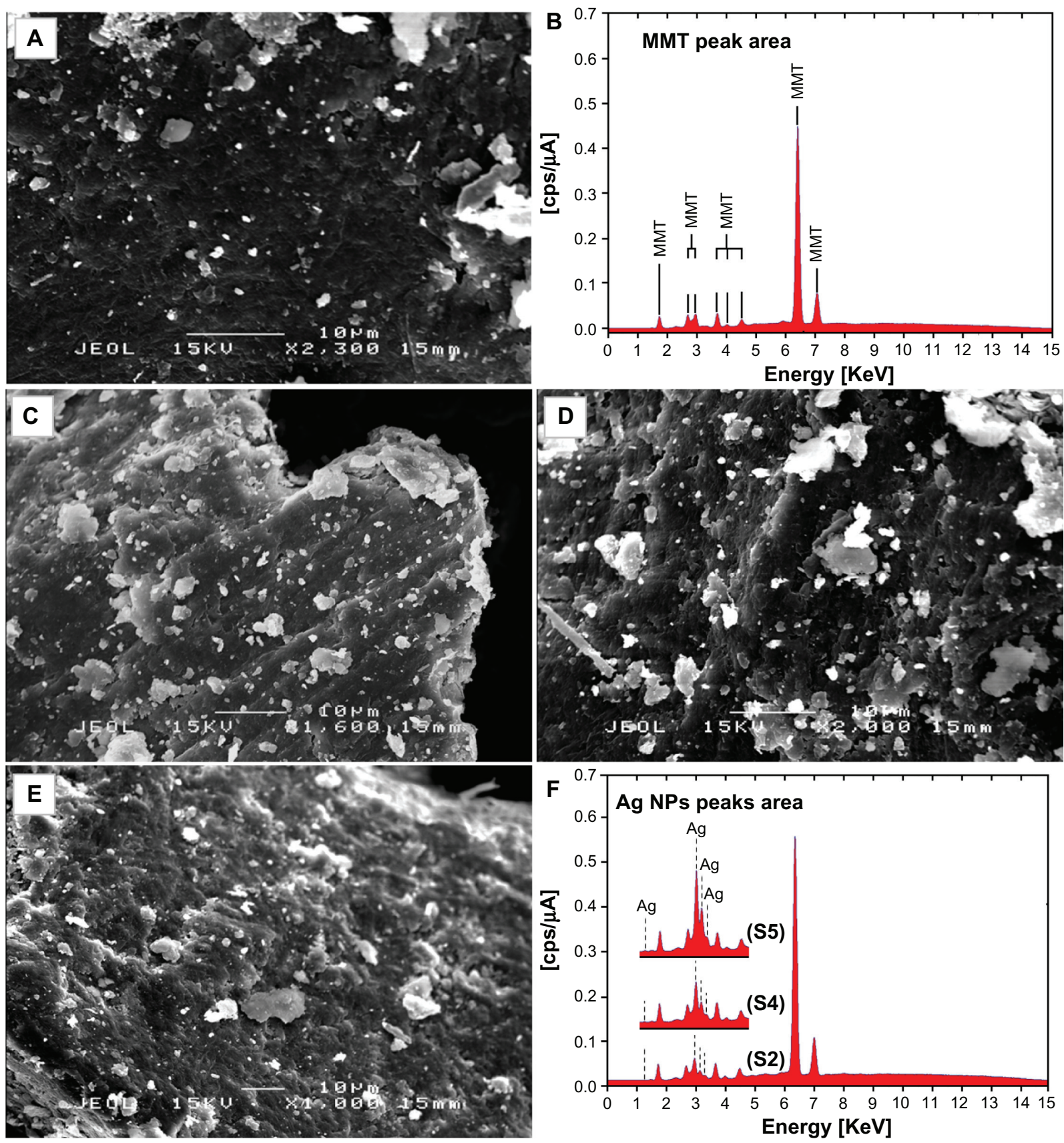

Figure 6 SEM micrographs and EDXRF spectra respectively for the MMT (A, B), Ag/MMT NCs at different $\mathrm{AgNO}_{3}$ concentrations: I.0\% (C), $2.0 \%(\mathbf{D}), 5.0 \%(\mathbf{E})$, and (F).

a similar diffraction profile and the PXRD peaks at $2 \theta$ of $38.28^{\circ}, 44.38^{\circ}, 64.52^{\circ}$, and 77.61 (Figure 4) could be attributed to the $111,200,220$, and 311 crystallographic planes of the face-centered cubic (fcc) silver crystals, respectively. ${ }^{44,45}$ In addition, there was a characteristic peak at about $2 \theta=62.10^{\circ}$ related to the MMT clay (PXRD Ref. No. 00-003$0010)$ as a stable substrate. The intensities of $111,200,220$, and 311 reflections due to the Ag NPs phase were also found to increase along with the increased Ag NPs in the solid support matrices.

\section{Morphology}

TEM images and their corresponding particle size distributions of Ag/MMT NCs containing different percentages of Ag NPs are shown in Figure 5. The TEM images and their size distributions revealed that the mean diameters and standard deviation of Ag NPs were about $4.19 \pm 1.37,6.74 \pm 1.76$, and $8.53 \pm 1.81 \mathrm{~nm}$ for $1.0 \%(\mathrm{a}-\mathrm{b}), 2.0 \%(\mathrm{c}-\mathrm{d})$, and $5.0 \%(\mathrm{e}-\mathrm{f})$, respectively. These results confirmed that the diameters of the Ag NPs synthesized in this method depended on the initial $\mathrm{AgNO}_{3}$ concentration. SEM images of the MMT and 


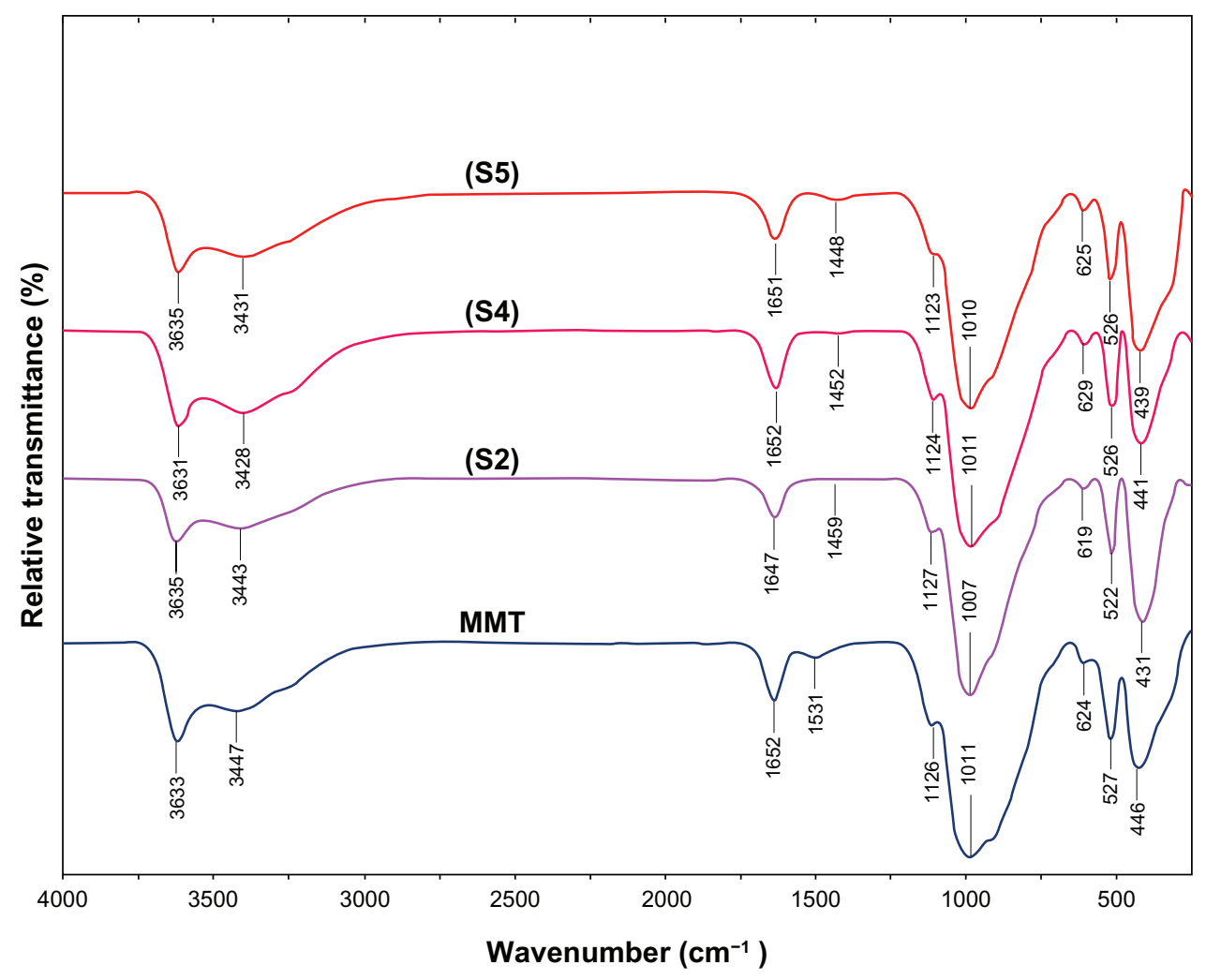

Figure 7 FT-IR spectra for the MMT and Ag/MMT NCs at different $\mathrm{AgNO}_{3}$ concentrations: (S2) I.0\%, (S4) $2.0 \%$, (S5) $5.0 \%$.

Ag/MMT (S2, S4, and S5) are presented in Figure 6. The surface morphology of MMT demonstrates a layered surface with some large flakes, which is a typical structure for MMT (Figure 6A and B). The exterior morphology for Ag/MMT NCs, show layered surfaces with large flakes and without significant morphological differences between them (Figures 6A, B, and C). Figure 6B, shows the EDXRF spectra for the MMT; the peaks around 1.7, 2.7, 2.9, 3.7, 4.0, 4.5, 6.4, and $7.1 \mathrm{keV}$ are related to the binding energies of MMT. In Figure 6F, the peaks around 1.3, 3.1,3.3, and $3.4 \mathrm{keV}$ are related to silver elements in the S2, S4, and S5. ${ }^{46}$ Additionally, the EDXRF spectra for the MMT and Ag/MMT NCs confirmed the presence of elemental compounds in the MMT and Ag NPs without any impurity peaks. Figure 6F demonstrates that with the increased percentages of Ag NPs in MMT (1\%, 2\%, and 5\%), after reduction, the intensity of Ag NPs peaks in the EDXRF spectra increased. The results indicate that the synthesized NCs were composed of high purity Ag NPs.

\section{FT-IR chemical analysis}

The FT-IR spectrum of MMT (Figure 7) showed the vibration bands at $3633 \mathrm{~cm}^{-1}$ for O-H stretching, $3447 \mathrm{~cm}^{-1}$ due to the inter-layered $\mathrm{O}-\mathrm{H}$ stretching (H bonding), at 1652

Table I Physical properties of Ag NPs in Ag/MMT NCs synthesized at different $\mathrm{AgNO}_{3}$ concentrations: (SI) 0.5\%, (S2) I.0\%, (S3) I.5\%, (S4) $2.0 \%$, and (S5) $5.0 \%$

\begin{tabular}{llllll}
\hline Samples & $\begin{array}{l}\text { Reaction volume } \\
\text { (lit) }\end{array}$ & $\lambda_{\max }{ }^{a}$ & Absorbance $^{\mathrm{b}}$ & $\begin{array}{l}\text { Approximated efficiency }_{(\%)} \\
\text { (\%) }\end{array}$ & $\begin{array}{l}\text { Ag NPs particle size }^{c} \\
(\mathbf{n m})\end{array}$ \\
\hline S1 & 0.50 & 396 & 0.91 & $98.04 \pm 1.45$ & $4.11 \pm 1.67$ \\
S2 & 1.00 & 398 & 1.17 & $96.23 \pm 1.39$ & $4.19 \pm 1.58$ \\
S3 & 1.50 & 400 & 1.91 & $95.40 \pm 2.67$ & $5.75 \pm 1.93$ \\
S4 & 2.00 & 402 & 2.34 & $89.24 \pm 2.14$ & $6.74 \pm 1.76$ \\
S5 & 5.00 & 406 & 3.72 & $85.57 \pm 4.28$ & $8.53 \pm 1.81$ \\
\hline
\end{tabular}

Notes: ${ }^{\mathrm{a}}$ The experiments were repeated three times and averaged to give the data in Table I; ${ }^{\mathrm{b}}$ The data were obtained by multiplying the absorbance of the corresponding diluted solutions by their dilution factors when diluted solutions were used for the data; 'The size of Ag NPs was determined by measuring diameters of about I00 nanoparticles in TEM image and by averaging them. 


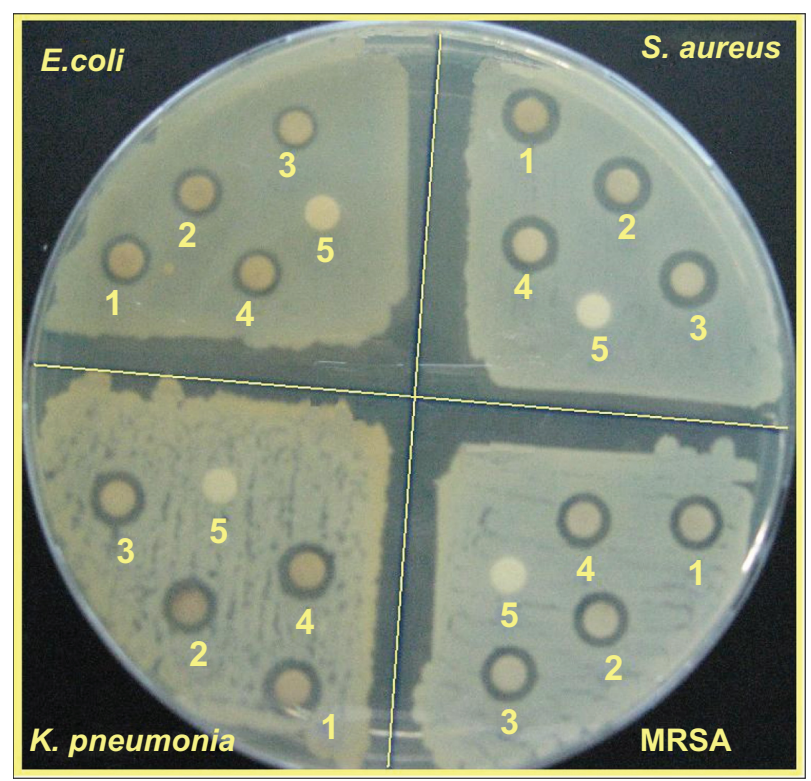

Figure 8 Comparison of the inhibition zone test between Gram-negative and Gram-positive bacteria (Escherichia coli, Klebsiella pneumoniae, Staphylococcus aureus, and methicillin-resistant S. aureus) form S0 (I), S2 (2), S4 (3), S5 (4), and MMT (5) respectively.

and $1531 \mathrm{~cm}^{-1}$ for $\mathrm{H}-\mathrm{O}-\mathrm{H}$ bending, 1126, 1011, and $910 \mathrm{~cm}^{-1}$ for Si-O stretching, $624 \mathrm{~cm}^{-1}$ for Al-OH, $910 \mathrm{~cm}^{-1}$ due to (A1, Mg)-OH vibration modes, and 527 and $446 \mathrm{~cm}^{-1}$ for Si-O bending. ${ }^{47}$ As shown in Figure 7, there were not many changes in the spectra of Ag/MMT NCs compared with MMT and peaks in S2, S4, and S5 shifted to lower wave numbers. The FT-IR spectra demonstrated the inflexibility of silicate layers and non-bond chemical interface between the silicate layers and Ag NPs in Ag/ MMT NCs (S2, S4, and S5). These results confirmed that with the increased amounts of Ag NPs in the Ag/MMT NCs due to the existence of van der Waals interactions between the oxygen groups of MMT and Ag NPs, peak areas shifted to low wave numbers and the intensity of peaks appearing in the range of 1459,1452 , and $1448 \mathrm{~cm}^{-1}$ increased.

\section{Inductively coupled plasma-optical emission spectroscopy}

After detecting the $\mathrm{Ag}^{+}$ions by using the ICP-OES spectroscopy, with the increased concentration of $\mathrm{AgNO}_{3}$ in $\mathrm{MMT}$ matrices and then the reduction by the reducing agent, the approximate efficiency gradually decreased from 98.04 to $96.23,95.40,89.24$, and finally 85.57 (\%) after S1, S2, S3, $\mathrm{S} 4$, and S5, respectively (Table 1). The results from the ICPOES analysis using a strong reducing agent, confirmed the formation of Ag NPs in MMT, which produced high yields.

\section{Antibacterial activity}

Inhibition zone values were obtained for the synthesized $\mathrm{AgNO}_{3} / \mathrm{MMT}$ suspension and Ag/MMT NCs (S2, S4, and S5) tested against E. coli, E. coli O157:H7, $K$. pneumoniae, $S$. aureus, and MRSA. The results and images of inhibition zones are presented as the average values in Table 2 and Figure 8, respectively. Table 2 shows that the $\mathrm{AgNO}_{3}$ and $\mathrm{Ag}$ NPs in MMT suspension gave high and similar antibacterial activity against Gram-negative and Gram-positive bacteria. Because of their size, Ag NPs can easily reach the nuclear content of bacteria and they present a large and impressive surface area, enabling broad contact with bacteria. ${ }^{48,49}$ This could be the reason why they give the best antibacterial effect. For solid support systems, some researchers have argued that $\mathrm{Ag}^{+}$ions released from the surface of Ag NPs are responsible for their antibacterial activity. ${ }^{50,51}$ For aqueous phase systems, the results show that the antibacterial test of $\mathrm{Ag}^{+}$ions is high at the concentration levels reached by releasing, and that the presence of Ag NPs is very important, which reinforces the idea that the larger the surface area the stronger the antibacterial activity. ${ }^{52}$ The diameters of inhibition zone in the agar plate are given in $\mathrm{mm}$. The tests were repeated three times for each treated sample, and the results are presented in Table 2. The suspension of

Table 2 Average inhibition zone and standard deviation for $\mathrm{MMT}, \mathrm{AgNO} / \mathrm{MMT}$ (SO), and $\mathrm{Ag} / \mathrm{MMT} \mathrm{NCs}$ at different $\mathrm{AgNO}{ }_{3}$ concentrations: (S2) $1.0 \%$, (S4) $2.0 \%$, and (S5) $5.0 \%$

\begin{tabular}{|c|c|c|c|c|c|c|c|}
\hline \multirow[t]{2}{*}{ Bacteria } & \multicolumn{4}{|c|}{ Inhibition zone $(\mathrm{mm})$} & \multirow{2}{*}{$\begin{array}{l}\text { Control negative } \\
\text { MMT ( } 10 \mathrm{mg} / \mathrm{mL})\end{array}$} & \multicolumn{2}{|c|}{ Control positive $(\mathrm{mm})$} \\
\hline & So & S2 & S4 & S5 & & CTX & C \\
\hline E. coli & $8.74 \pm 0.23$ & $8.30 \pm 0.13$ & $7.32 \pm 0.14$ & $8.07 \pm 0.10$ & NA* & 22.84 & 18.90 \\
\hline E. coli OI57:H7 & $10.74 \pm 0.32$ & $9.80 \pm 0.41$ & $7.82 \pm 0.10$ & $7.36 \pm 0.21$ & NA & 30.01 & 20.84 \\
\hline K. pneumoniae & $10.98 \pm 0.17$ & $10.38 \pm 0.30$ & $9.56 \pm 0.30$ & $9.72 \pm 0.32$ & NA & 31.04 & 24.69 \\
\hline S. aureus & $10.02 \pm 0.10$ & $9.95 \pm 0.10$ & $9.52 \pm 0.14$ & $9.38 \pm 0.21$ & NA & 27.78 & 20.14 \\
\hline MRSA & $8.97 \pm 0.27$ & $9.21 \pm 0.13$ & $8.98 \pm 0.04$ & $9.04 \pm 0.17$ & NA & 18.91 & 15.54 \\
\hline
\end{tabular}

Abbreviations: *NA, not appearing; MMT, montmorillonite; MRSA, methicillin-resistant Staphylococcus aureus; CTX, cefotaxime; C, chloramphenicol. 
MMT (10 mg/mL), showed no antibacterial activity. The $\mathrm{AgNO}_{3} / \mathrm{MMT}$ suspension for all tested bacteria showed high antibacterial activity and, interestingly, these effects in the Ag/MMT NCs (S2, S4 and S5) were increased with the decreasing size of Ag NPs. Although other analysis in this study showed that in the Ag/MMT NCs (S2, S4 and S5) the amounts of Ag NPs present gradually increased, and that higher Ag NPs loadings do not lead to superior antibacterial activity.

\section{Conclusion}

The Ag NPs were successfully prepared from the $\mathrm{AgNO}_{3} /$ MMT suspension at the different $\mathrm{AgNO}_{3}$ concentration by using sodium borohydride at room temperature. The surface of MMT fostered the nucleation of Ag NPs during the reduction process. A small number of Ag NPs intercalated between bordering MMT lamellar layers, but the majority of the Ag NPs indicated by the PXRD signal, and that appeared in the TEM, form simply at the outer surface of MMT layers. The distribution size of Ag NPs indicated that larger particle sizes of Ag NPs were obtained when the concentration of $\mathrm{Ag}^{+}$ions increased. The average sizes of the $\mathrm{Ag}$ NPs were around $4.19,6.74$, and $8.53 \mathrm{~nm}$ for $\mathrm{S} 2, \mathrm{~S} 4$, and $\mathrm{S} 5$, respectively. The interlayer spaces of MMT were increased and shifted at low $2 \theta$ angles for Ag/MMT NCs, which confirmed the intercalation structures. Moreover, the PXRD analysis confirmed that the crystallographic planes of the silver crystal were the fcc types. The UV-visible absorption spectra showed the peak characteristic of the SPR bond of Ag NPs. SEM images show that the external morphology for MMT and Ag/MMT NCs illustrate layered surfaces with large flakes, and with no noteworthy morphological distinctions between them. EDXRF spectra confirmed the presence of elemental compounds in the MMT and Ag NPs with no contamination peaks. The antibacterial activities of Ag/MMT NCs at the different particle size of Ag NPs showed antibacterial activity against the Gram-negative and Gram-positive bacteria. These results show that the antibacterial resistance of Ag NPs in MMT can be modified with the size of Ag NPs, and decreases with the increase in particle size. Needless to say, further studies are required to investigate the biological effects of Ag/MMT NCs on the types of bacteria, in order to extend this subject area.

\section{Acknowledgments}

The authors are grateful to the staff of the Department of Chemistry, Universiti Putra Malaysia, for their help in this research, to the Institute of Bioscience for technical assistance, and also to Mrs Parvaneh Shabanzadeh for her contribution to the study.

\section{Disclosure}

The authors have no conflicts of interest to disclose in this work.

\section{References}

1. Zhu HY, Orthman JA, Li JY, et al. Novel composites of $\mathrm{TiO}_{2}$ (anatase) and silicate nanoparticles. Chem Mater. 2002;14:5037-5044.

2. Choy JH, Park JH. Yoon JB. Multilayered $\mathrm{SiO}_{2} / \mathrm{TiO}_{2}$ nanosol particles in two-dimensional aluminosilicate catalyst-support. J Phys Chem B. 1998;102:5991-5995.

3. Mogyorosi K, Dékány I, Fendler JH. Preparation and characterization of clay mineral intercalated titanium dioxide nanoparticles. Langmuir. 2003;19:2938-2946.

4. Miao S. Liu Z, Han B, et al. Synthesis and characterization of $\mathrm{TiO}_{2}$-montmorillonite nanocomposites and their application for removal of methylene blue. J Mater Chem. 2006;16:579-584.

5. Rasal RM, Janorkar AV, Hirt DE. Poly(lactic acid) modifications. Prog Polym Sci. 2010;35:338-356.

6. Paap AS, Dekany I. Preparation of $\mathrm{Pd}^{\circ}$ nanoparticles stabilized by polymers and layered silicate. Appl Clay Sci. 2001;19: 155-172.

7. Belova V, Möhwald H, Shchukin DG. Sonochemical intercalation of preformed gold nanoparticles into multilayered clays. Langmuir. 2008;24:9747-9753.

8. Kozak M, Domka L. Adsorption of the quaternary ammonium salts on montmorillonite. J Phys Chem Solids. 2004;65:441-445.

9. Paek SM, Jang JU, Hwang SJ, et al. Exfoliation restacking route to Au nanoparticle clay nanohybrids. J Phys Chem Solids. 2006;67: 1020-1023.

10. Kwiatkowski KC, Lukehart CM. Nanocomposites prepared by sol-gel methods: synthesis and characterization. Nalwa HS, editor. Nanostructured Materials and Technology. London: Academic Press; 2002:57-91.

11. Praus $\mathrm{P}$, Turicová M, Valášková M. Study of silver adsorption on montmorillonite. J Braz Chem Soc. 2008;19:549-556.

12. Valášková M, Martynková GS, Lešková J, et al. Silver nanoparticles/ montmorillonite composites prepared using nitrating reagent at water and glycerol. J Nanosci Nanotechnol. 2008;8:3050-3058.

13. Ayyappan S, Subbanna GN, Gopalan RS, et al. Nanoparticles of nickel and silver produced by the polyol reduction of the metal salts intercalated in montmorillonite. Solid State Ionics. 1996;84:271-281.

14. Patakfalvi RA, Oszka A, Dekany I. Synthesis and characterization of silver nanoparticles/kaolinite composites. Colloid Surfaces Physicochem Eng Aspect. 2003;220:45-54.

15. Huang H, Yang Y. Preparation of silver nanoparticles in inorganic clay suspensions. Compos Sci Technol. 2008;68:2948-2953.

16. Temgire MK, Joshi SS. Optical and structural studies of silver nanoparticles. Radiat Phys Chem. 2004;71:1039-1044.

17. Kapoor S. Preparation, characterization, and surface modification of silver particles. Langmuir. 1998;14:1021-1025.

18. Tsuji T, Thang DH, Okazaki Y, et al. Preparation of silver nanoparticles by laser ablation in polyvinylpyrrolidone solutions. Appl Surf Sci. 2008; 254:5224-5230.

19. Luo Y. Preparation of silver nanoparticles by heating a quaternary ammonium polyelectrolyte AgNO3 aqueous solution in basic conditions. Indian J Chem. 2007;46:1266-1269.

20. Zhang Y, Chen F, Zhuang J, et al. Synthesis of silver nanoparticles via electrochemical reduction on compact zeolite film modified electrodes. Chem Comm. 2002 Dec 7;2814-2815.

21. Szczepanowicz K, Stefańska J, Socha RP. Preparation of silver nanoparticles via chemical reduction and their antimicrobial activity. Physicochem Probl Miner Process. 2010;45:85-98. 
22. Nisaratanaporn E, Wongsuwan K. Preparation of ultrafine silver powder using glycerol as reducing agent. J Miner Met Mater Soc. 2008; 18:1-5.

23. Pastoriza-Santos I, Liz-Marzán LM. Formation and stabilization of silver nanoparticles through reduction by N,N-dimethylformamide. Langmuir. 1999;15:948-951.

24. Raveendran P, Fua J, Wallen SL. A simple and "green" method for the synthesis of $\mathrm{Au}, \mathrm{Ag}$, and $\mathrm{Au}-\mathrm{Ag}$ alloy nanoparticles. Green Chem. 2006;8:34-38.

25. Setua P, Pramanik R, Sarkar S. Synthesis of silver nanoparticles inside the nonaqueous ethylene glycol reverse micelle and a comparative study to show the effect of the nanoparticle on the reverse micellar aggregates through solvation dynamics and rotational relaxation measurements. J Phys Chem B. 2010;114:7557-7564.

26. Praus P, Turicová M, Klementová M. Preparation of silvermontmorillonite nanocomposites by reduction with formaldehyde and borohydride. J Braz Chem Soc. 2009;20:1351-1357.

27. Sun L, Zhang Z, Dang H. A novel method for preparation of silver nanoparticles. Mater Lett. 2003;57:3874-3879.

28. Panáček A, Kvĭtek L, Prucek R, et al. Silver colloid nanoparticles: synthesis, characterization, and their antibacterial activity. J Phys Chem B. 2006;110:16248-16243.

29. Pal S, Tak YK, Song JM. Does the antibacterial activity of silver nanoparticles depend on the shape of the nanoparticle? A study of the Gram-negative bacterium Escherichia coli. Appl Environ Microbiol. 2007;73:1712-1720.

30. Ulkur E, Oncul O, Karagoz H, et al. Comparison of silver-coated dressing $\left(\right.$ Acticoat $\left.^{\mathrm{TM}}\right)$, chlorhexidine acetate $0.5 \%$ (Bactigrass $\left.^{\mathbb{R}}\right)$, and fusidic acid $2 \%$ (Fucidin $^{\circledR}$ ) for topical antibacterial effect in methicillin-resistant Staphylococci-contaminated, full-skin thickness rat burn wounds. Burns. 2005;31:874-877.

31. Bosetti M, MassèA, Tobin E, et al. Silver coated materials for external fixation devices: in vitro biocompatibility and genotoxicity. Biomaterials. 2002;23:887-892.

32. Gauger A, Mempel M, Schekatz A, et al. Silver coated textiles reduce Staphylococcus aureus colonization in patients with atopic eczema. Dermatology. 2003;207:15-21.

33. Ahmad MB, Shameli K, Yunus WMZW, et al. Synthesis and characterization of silver/clay/starch bionanocomposites by green method. Aust J Basic Appl Sci. 2010;4:2158-2165.

34. Ahmad MB, Shameli K, Darroudi M, et al. Synthesis and characterization of silver/clay nanocomposites by chemical reduction method. Am J Appl Sci. 2009;6:1909-1914.

35. Shameli K, Ahmad MB, Yunus WMZW, et al. Synthesis and characterization of silver/talc nanocomposites using the wet chemical reduction method. Int J Nanomedicine. 2010;5:743-751.

36. Ahmad MB, Shameli K, Darroudi M, et al. Synthesis and characterization of silver/clay/chitosan bionanocomposites by UV-irradiation method. Am J Appl Sci. 2009;6:2030-2035.
37. Shameli K, Ahmad MB, Yunus WMZW, et al. Green synthesis of silver/ montmorillonite/chitosan bionanocomposites using the UV irradiation method and evaluation of antibacterial activity. Int J Nanomedicine. 2010;5:875-887.

38. Darroudi M, Ahmad MB, Shameli K, et al. Synthesis and characterization of UV-irradiated silver/montmorillonite nanocomposites. Solid State Sci. 2009;11:1621-1624.

39. Shameli K, Ahmad MB, Yunus WMZW, et al. Synthesis of silver/ montmorillonite nanocomposites using $\gamma$-irradiation. Int J Nanomedicine. 2010;5:1067-1077.

40. Benn TM, Westerhoff P. Nanoparticle silver released into water from commercially available sock fabrics. Environ Sci Technol. 2008;42: 4133-4139.

41. Song KC, Lee MS, Park TS, et al. Preparation of colloidal silver nanoparticles by chemical reduction method. Korean J Chem Eng. 2009;26: 153-155.

42. Aihara N, Torigoe K, Esumi K. Preparation and characterization of gold and silver nanoparticles in layered laponite suspensions. Langmuir. 1998;14:4945-4949.

43. Xu GN, Qiao XL, Qiu XL, e al. Preparation and characterization of stable monodisperse silver nanoparticles via photoreduction. Colloid Surface A. 2008;320:222-226.

44. Shin HS, Yang HJ, Kim SB, et al. Mechanism of growth of colloidal silver nanoparticles stabilized by polyvinyl pyrrolidone in $\gamma$-irradiated silver nitrate solution. J Colloid Interface Sci. 2004;274:89-94.

45. Prasad V, Souza CD, Yadav D, et al. Spectroscopic characterization of zinc oxide nanorods synthesized by solid state reaction. Spectrochimica Acta Part A Mol Biomol Spectrosc. 2006;65:173-178.

46. Bar H, Bhui DK, Sahoo GP, et al. Green synthesis of silver nanoparticles using latex of Jatropha curcas. Colloid Surface A. 2009;339: 134-139.

47. Alemdar A, Güngör N, Ece OI, et al. The rheological properties and characterization of bentonite dispersions in the presence of non-ionic polymer PEG. J Mater Sci. 2005;40:171-177.

48. Chudasama B, Vala AV, Andhariya N, et al. Enhanced antibacterial activity of bifunctional $\mathrm{fe}_{3} \mathrm{O}_{4}$ core-shell nanostructures. Nano Res. 2009; 2:955-965.

49. Chen SF, Li JP, Qian K, Xu WP, et al. Large scale photochemical synthesis of $\mathrm{M} @ \mathrm{TiO} 2$ nanocomposites $(\mathrm{M}=\mathrm{Ag}, \mathrm{Pd}, \mathrm{Au}, \mathrm{Pt})$ and their optical properties, $\mathrm{CO}$ oxidation performance, and antibacterial effect. Nano Res. 2010;3:244-255.

50. Morones JR, Elechiguerra JL, Camacho A, et al. The bactericidal effect of silver nanoparticles. Nanotechnology. 2005;16:2346-2353.

51. Lee D, Cohen RE, Rubner MF. Antibacterial properties of Ag nanoparticle loaded multilayers and formation of magnetically directed antibacterial microparticles. Langmuir. 2005;21: 9651-9659.

52. Jeong SH, Hwnag YH, Yi SC. Antibacterial properties of padded PP/PE nonwovens incorporating nano-sized silver colloids. J Mater Sci. 2005;40:5413-5418.
International Journal of Nanomedicine

\section{Publish your work in this journal}

The International Journal of Nanomedicine is an international, peerreviewed journal focusing on the application of nanotechnology in diagnostics, therapeutics, and drug delivery systems throughout the biomedical field. This journal is indexed on PubMed Central, MedLine, CAS, SciSearch ${ }^{\circledR}$, Current Contents ${ } /$ Clinical Medicine, Journal

\section{Dovepress}

Citation Reports/Science Edition, EMBase, Scopus and the Elsevier Bibliographic databases. The manuscript management system is completely online and includes a very quick and fair peer-review system, which is all easy to use. Visit http://www.dovepress.com/ testimonials.php to read real quotes from published authors. 